\title{
BOURDIEU E O FENÔMENO ESTÉTICO: ganhos e limites de seu conceito de campo literário
}

\author{
Maurício Vieira Martins
}

Se a importância de um intelectual pode ser aferida através da influência que ele exerce num certo espaço de debates, então a posição do sociólogo francês Pierre Bourdieu, falecido ao início de 2002, é realmente privilegiada. Segundo os registros do Social sciences citation index, ele foi, recorrentemente, um dos autores mais citados da área de ciências sociais nos últimos anos, gerando uma verdadeira escola de pensamento. Com produção diversificada, abrangendo temas que vão desde a moda até seu amplo estudo sobre $A$ miséria no mundo, a repercussão dos trabalhos de Bourdieu é de fato considerável. Dentro da vasta produção do autor, um feixe de questões ocupa um lugar de destaque: a sua sociologia dos campos, e é precisamente um aspecto determinado deste feixe que será objeto do artigo que se segue.

Artigo recebido em junho/2003

Aprovado em junho/2004
Mais especificamente, estaremos interessados em discutir as características daquilo que Bourdieu nomeia como o campo literário (conceito cuja definição mais minudente será feita logo adiante): espaço social que reúne diferentes grupos de literatos, romancistas e poetas, que mantêm relações determinadas entre si e também com o campo do poder. Analisando esta vertente do pensamento de Bourdieu, tentaremos mostrar que sua peculiar aproximação às obras produzidas pelo campo literário acaba por colocar em evidência alguns aspectos ainda pouco examinados de sua própria teoria geral dos campos, donde a relevância de se proceder a tal discussão.

Adiantando parte da argumentação a ser aqui desenvolvida, o presente artigo sustenta uma hipótese dupla: num primeiro momento, reconheceremos, com Bourdieu, a fecundidade de sua proposta de análise, que ilumina nas obras literárias uma série de relações que, de outra maneira, per- 
maneceriam invisíveis. Acompanhando o autor, concordamos com a necessidade de se romper com uma certa representação ingênua do fenômeno estético (em particular, do texto literário), que subscreve ainda hoje uma teoria do gênio criador movido por causas simplesmente inexplicáveis.

Já num segundo momento do artigo, mas agora distanciando-nos de Bourdieu, será desenvolvido o argumento de que, em que pese a produtividade de sua abordagem, ela muitas vezes desconsidera a dimensão propriamente singular do fenômeno estético, equiparando-o a outras dimensões da experiência humana que a rigor são bastante heterogêneas. Daí a necessidade de algum outro tipo de apreciação suplementar que consiga manter uma relação mais afirmativa com a singularidade do fenômeno estético e do texto literário. Relação que reconheça inclusive que este último possui o que outros autores conceituam como um excesso de significação: capacidade de ultrapassar o estrito momento histórico em que foi produzido rumo a uma dimensão temporal mais ampla.

Ao final do artigo, recorreremos também, como exemplo de contraste, aos ensaios de Walter Benjamin sobre o poeta francês Charles Baudelaire. A escolha de Benjamin não foi arbitrária, ela se deveu ao fato de este filósofo alemão ter estudado um período histórico próximo ao analisado por Bourdieu (a produção literária na Paris do Segundo Império), com ênfase na obra de Baudelaire, autor também abordado por Bourdieu em seu livro As regras da arte. Não obstante esta proximidade do objeto empírico, veremos que as conclusões apresentadas pelos dois autores são tão distintas que merecem uma problematização mais detalhada.

$\mathrm{Na}$ verdade, o leitor observará que as conseqüências do que está aqui em jogo não se referem apenas ao debate envolvendo literatos de renome do século XIX. Bem mais do que isso, avulta em importância uma questão conceitual de fundo, que diz respeito a um certo modo de aproximação ao texto literário (e, em última instância, à capacidade de ação consciente dos sujeitos). Modo este que se presentifica, devido à enorme influência de Bourdieu não apenas na
Europa mas também no Brasil, inclusive em setores importantes da crítica sociológica em nosso país. Por exemplo: a matriz subjacente a certas controvérsias sobre o estudo sociológico de nossa intelectualidade (embora não seja exatamente este o tema do presente artigo) tem sua origem última na própria teoria dos campos de Bourdieu, razão suplementar para um olhar atento sobre ela.

Iniciemos, então, com a referida teoria dos campos; bem conhecida do público leitor em ciências sociais, ela certamente não necessita ser aqui reproduzida em detalhes. Apenas como registro de seus traços mais essenciais, recordemos a sintética definição que o próprio Bourdieu nos apresenta de seu cerne no texto Questões de sociologia. Ali, ele define campos como

[...] espaços estruturados de posições (ou de postos) cujas propriedades dependem das posições nestes espaços, podendo ser analisadas independentemente das características de seus ocupantes [...]. Há leis gerais dos campos: campos tão diferentes como o campo da política, o campo da filosofia, o campo da religião possuem leis de funcionamento invariantes (Bourdieu, 1983, p. 89, grifos do autor).

Assim, um campo é um espaço social onde seus participantes se engajam em relações recíprocas no transcurso de suas atividades, e a passagem citada nos esclarece que campos muito diferentes entre si (como o da política, o da religião etc.) apresentam propriedades comuns que permitem que se possa falar em leis características deles. Quanto ao ganho cognitivo que tal teoria oferece, ele pode ser visto como uma tentativa de evidenciar que ali onde pensávamos que havia um sujeito livre, agindo de acordo com sua vontade mais imediata, na verdade o que existe é um espaço de forças estruturado que molda a capacidade de ação e de decisão de quem dele participa. É, pois, contra uma certa concepção de autonomia do sujeito que Bourdieu se insurge de modo enfático. E, ao longo de seu trajeto intelectual, ele elegeu sucessivos objetos onde seria pos- 
sível detectar a vigência de uma subjacente rede de relações coagindo os sujeitos: a educação, a moda, a televisão, a produção intelectual e artística de uma época etc.

No que diz respeito ao campo literário, tema aqui em foco, embora um primeiro contato com ele possa sugerir uma infinita casuística de querelas e tomadas de posições contraditórias entre seus membros, o que o desenvolvimento da análise sociológica evidencia é que "este universo aparentemente anárquico e de bom grado libertário [...] é o lugar de uma espécie de balé bem ordenado no qual os indivíduos e os grupos desenham suas figuras" (1996, p. 133).

A tarefa que Bourdieu se propõe é algo como proceder à decifração das regras que comandam a coreografia deste balé. E ele faz isso de maneira persuasiva, demostrando que as oscilações nas tomadas de posição dos artistas e literatos correspondem às metamorfoses do relacionamento existente entre os artistas e o campo econômico e político. Esta demonstração explicita as condições sociais de possibilidade de emergência destes grupos, o que finda por invalidar uma teoria romântica do artista como gênio, que produziria unicamente em função de sua inspiração. Tomando como estudo de caso o campo literário da França de meados do século XIX, Bourdieu identifica um verdadeiro microcosmo tripartido, cujos participantes estavam postos em simultâneas relações de concorrência e solidariedade entre si, que repercutiam em sua produção literária. Assim, especialmente a partir de Napoleão III, teríamos os defensores de uma arte social, que entendiam que a elaboração artística deveria expressar os conflitos presentes na sociedade (como a questão das desigualdades, da miséria etc.), coexistindo com os defensores da arte pela arte, cujo investimento maior era feito nas questões da linguagem artística, que secundarizavam os conteúdos abordados em nome de uma pesquisa sempre renovada da linguagem. Finalmente, haveria aqueles literatos que endereçavam sua produção diretamente ao mercado (os artistas burgueses), que produziam obras de consumo imediato, com bom retorno financeiro, mas desprovidas de maiores preocupações substantivas ou formais (1974, pp.192-193).
Bourdieu se interessa em particular pelos defensores da arte pela arte, que geraram nomes mundialmente célebres (como Gustav Flaubert e Charles Baudelaire), marcos na literatura universal. E ele nos mostra de forma provocativa que havia subjacentes determinações de classe operando nas tomadas de posição, em aparência puramente estéticas, dos diferentes participantes deste campo. Pois enquanto os defensores da arte social eram, na maior parte das vezes, indivíduos oriundos de classes médias e até populares, já os defensores da arte pela arte vinham de camadas mais abastadas da sociedade francesa, que podiam esperar por um grande tempo o reconhecimento material $\mathrm{e}$ simbólico de seu trabalho: "Era preciso ser burguês e dispor, portanto, dos recursos necessários a fim de poder resistir à solicitação direta da demanda e esperar pelas remunerações materiais e simbólicas necessariamente adiadas" (Bourdieu, 1974 , p. 200, grifos do autor).

A ênfase de seus membros nos temas sobretudo formais teria também o efeito de, no limite, apagar as marcas sociais e históricas que pudessem vincular a obra a um certo contexto. (É por aí que se explicaria o desejo de Flaubert de escrever um "livro sobre o nada, um livro sem vínculos exteriores".) Estaríamos então diante de um projeto de autonomia acalantado pelos intelectuais e artistas, que ansiavam por um reconhecimento de seu valor peculiar, supostamente irredutível ao mercado e ao cotidiano de uma sociedade já mercantilizada em suas demais esferas. Daí Bourdieu referir-se a eles como a "fração dominada da classe dominante" (1974, p. 192), que mantinha relações ambivalentes com o poder, ora desprezando os "burgueses" - na verdade sua clientela em potencial -, mas ao mesmo tempo desejando um reconhecimento público que podia demorar enormemente.

Para fundamentar esta hipótese, Bourdieu nos apresenta pronunciamentos realmente extremos de alguns dos defensores da arte pela arte, que colocam em evidência uma visão de mundo onde marcas de um pertencimento de classe se manifestam com força. Com efeito, podemos surpreender autênticas pérolas do pensamento conservador, presentes mesmo naqueles que se apresentavam como 
inovadores radicais. Ouçamos, por exemplo, qual é a premissa, no entendimento de E. Goncourt, para se ser um "homem de talento": "Talvez seja um preconceito, mas acredito que é preciso ser um homem de bem e um burguês honrado para ser um homem de talento. Julgo a partir de Flaubert e de nós [...]" (apud Bourdieu, 1974, p. 195).

Quanto ao próprio Flaubert - o chefe da escola -, suas preferências elitistas são claramente exteriorizadas em suas cartas: "Acreditais que se a França, em lugar de ser governada pela multidão, estivesse em poder dos mandarins, nós estaríamos assim? Em lugar de haver desejado esclarecer as classes baixas, teria sido melhor tratar de instruir as altas" (Idem, p. 194).

Como a realidade política francesa estava muito distante dos desejos do romancista, a alternativa encontrada por ele era assim proclamada: "Eu me enfio em meu buraco e, mesmo que o mundo desabe, eu não saio do lugar. A ação [...] me parece cada vez mais antipática" (Idem, p. 196).

Estes depoimentos de escritores tão relevantes acerca de seu posicionamento no mundo social e político fornecem a Bourdieu a oportunidade de aplicar a eles o seu conceito de habitus, entendido como o conjunto das disposições inconscientes que estariam presentes em diferentes sujeitos, levando-se em conta - o que é decisivo - que tais disposições seriam o resultado da interiorização de complexas estruturas objetivas presentes numa sociedade (1974, p. 201). Ora, condições sociais distintas produzem nos sujeitos disposições distintas e, conseqüentemente, habitus de classe: grupos identificáveis de subjetividades que, partilhando certas características em comum, se articulam por esta via indireta com as diferenciadas posições objetivas das classes sociais.

No que toca aos defensores da arte pela arte, Bourdieu sustenta que havia uma afinidade estrutural entre certas posições disponíveis no campo literário e aqueles indivíduos em condições de ocupá-las. Dito de outro modo: o que para o literato, de seu ponto de vista subjetivo, se assemelha sobretudo a uma vocação inquestionável, produto de um talento pessoal e intransferivel, seria visualizado com maior clareza pela análise sociológica quando confrontado com aquelas disponibilida- des existentes num certo momento bistórico, que demandam ser ocupadas por alguns sujeitos - $e$ apenas por alguns - compativeis com elas.

O habitus desempenha portanto a função de uma estrutura intermediária, que realiza a mediação entre as chamadas condições objetivas de funcionamento de uma sociedade (a existência de um mercado, que pressupõe a divisão entre trabalho material e intelectual, o estágio em que se encontram as relações entre as classes sociais e a esfera política etc.) e as aptidões subjetivas dos membros desta sociedade, vividas algo ingenuamente por estes últimos como talentos inatos.

Inicialmente, as pesquisas de Bourdieu sobre o campo literário francês da segunda metade do século XIX foram apresentadas em seus escritos da década de 1970 (em "Le temps modernes" e em "Scolies"). Anos mais tarde, ele amplia e sistematiza suas concepções em As regras da arte, texto fundamental para todo leitor que se interesse por estética. Nele, é realizado um comentário bastante original sobre A educação sentimental, romance de Gustav Flaubert que, no entendimento do sociólogo, não teria sido analisado da forma mais apropriada até o presente momento.

Discutindo este romance, a tese mais geral de Bourdieu é a de que

[...] a estrutura da obra, que uma leitura estritamente interna traz à luz, ou seja, a estrutura do espaço social no qual transcorrem as aventuras de Frédéric [personagem central de $A$ educação sentimentall, é também a estrutura do espaço social no qual seu próprio autor estava situado (1996, p. 17).

Dessa forma, existiria um paralelismo - a ser posto em evidência pela análise sociológica - entre o texto literário e o espaço social em que ele foi produzido. Para comprovar essa hipótese central, Bourdieu afirma que as desventuras do jovem protagonista de A educação sentimental, Frédéric, expressam as tensões que marcam um membro do proprietariado que, tendo dificuldades em assumir a herança de sua família, oscila entre espaços sociais distintos (o personagem circula entre os salões de empresários mas também nas reuniões dos literatos intelectualizados). 
Resta Frédéric. Herdeiro que não quer tornar-se o que é, ou seja, um burguês, ele oscila entre estratégias mutuamente exclusivas e, à força de recusar os possíveis que lhe são oferecidos [...] acaba por comprometer todas as suas possibilidades de reprodução (Idem, p. 33).

Como vemos, a análise empreendida por Bourdieu tem um salutar efeito desmistificador de ruptura com a "relação encantada" que uma certa crítica literária mantém com o fenômeno estético. Para os que subscrevem uma teoria da criação literária movida por uma espécie de inefável (e esta crença é ainda hoje bastante difundida, basta ver os enunciados de um filósofo tão relevante como H. G. Gadamer, citado logo ao início de $A s$ regras da arte pelo próprio Bourdieu), a leitura de seus textos é um antídoto eficaz. Pois eles nos apresentam de forma contundente os personagens literários se debatendo no interior de subjacentes estruturas sociais, que possuem uma inteligibilidade própria, a ser desvendada pela análise literária de cunho sociológico.

\section{$* * *$}

Porém, percorrido este trajeto, que é certamente instrutivo, diríamos que uma importante questão não foi abordada pela sociologia bourdieusiana, e é precisamente dela que nos ocuparemos a partir de agora. Referimo-nos à possibilidade de a obra literária exceder sua determinação sociológica originária e vir a se constituir como força geradora de sentido, ultrapassando o contexto imediato em que foi produzida. Quando isso ocorre, ela consegue operar sobre a mundanidade que a gerou a transfiguração estética trabalho próprio da expressão artística -, demandando uma apreensão singularizada que acolha esta inovação trazida pela própria obra. Examinemos novamente, mas agora levando em conta esta ressalva, aquela passagem anteriormente citada, que apresenta ao leitor a hipótese central de Bourdieu sobre A educação sentimental:

[...] a estrutura da obra, que uma leitura estritamente interna traz à luz, ou seja, a estrutura do espaço social no qual transcorrem as aventuras de Fréderic, é também a estrutura do espaço social no qual seu próprio autor estava situado (1996, p. 17).

Ora, o que está ausente em passagens como esta é a possibilidade de a obra (o romance, o poema, a novela) ultrapassar a homologia com o espaço social em que foi produzida e gerar o seu próprio espaço estético, que mesmo lançando raízes profundas no convívio dos homens, não deve ser assimilado a este último de forma tão direta. A possibilidade de a obra literária exceder o campo literário no qual foi produzida e gerar como que círculos concêntricos que se expandem ao longo do tempo pode ser demonstrada de várias maneiras, como veremos a seguir.

Inicialmente, talvez caiba prosaicamente recordar que no Brasil, na cidade do Rio de Janeiro, no ano de 2002 foram encenadas simultaneamente nada menos do que oito peças de Shakespeare, escritas originalmente na Inglaterra do século XVII. E, é duro dizer, a sociologia dos campos de Bourdieu, tão fértil sob outros aspectos, tem muito pouco a dizer acerca das possíveis razões que expliquem a perenidade desta dramaturgia que nos convida, tantos séculos depois, a refletirmos sobre o mundo e sobre nós mesmos. Com efeito, o que o exemplo de um Shakespeare nos mostra com clareza é que a estrutura da obra - para usarmos a expressão de Bourdieu -, nem sempre é apenas "a estrutura do espaço social no qual seu próprio autor estava situado", pois ela pode ultrapassar este último (o espaço social do autor) rumo à sua própria existência singular como fenômeno estético.

Mais do que isso: se permanecêssemos apenas na estrutura do espaço social do autor como chave explicativa da obra, teríamos enormes dificuldades em entender sua recepção em sociedades e tempos históricos muito distintos daqueles nos quais a obra foi originalmente produzida. Afirmar isso não significa acreditar numa espécie de inefável que estaria presente no texto literário (como parece ser o caso de um H. G. Gadamer, justamente criticado por Bourdieu); significa, apenas, atentar para a necessidade de uma sintonia mais fina com determinadas manifestações estéticas, a fim de reconbecer a potência nelas presente. 
Ao invés de reconhecer esta riqueza da obra, Bourdieu opta recorrentemente por caracterizá-la apenas através das marcas de seu meio social mais próximo. Mesmo na abordagem de $A$ educação sentimental (o comentário mais minudente feito por Bourdieu sobre um texto literário) esta tendência se manifesta com freqüência. Tomemos como exemplo a análise do relacionamento entre os personagens Frédéric e seu amigo Deslauriers. Ali onde vários intérpretes detectaram um conjunto complexo de sentimentos contraditórios, afetos ambivalentes, tensões psíquicas permeadas por relações de classe, Bourdieu parece se satisfazer apenas com esta última determinação. Assim, ele afirma de forma taxativa: "A relação entre Frédéric e Deslauriers desenha a oposição entre aqueles que herdam e aqueles que herdam apenas a aspiração a possuir, ou seja, entre burguês e pequeno-burguês". E, mais adiante: "O princípio da relação singular entre os dois amigos está inscrito na relação entre a burguesia e a pequena burguesia” (1996, pp. 29-30).

Obviamente, não se trata de negar a presença de fortes determinações de classe no interior do relacionamento entre estes dois personagens; $\mathrm{O}$ que convém questionar é apenas a implícita suposição de que o texto literário se esgota nesta dimensão, como se ele não apresentasse outras possibilidades de aproximação. Por outro lado, é fato que, quando se trata de analisar $A$ educação sentimental, as teses de Bourdieu muitas vezes se revelam fecundas, talvez em função de uma percepção muito aguda do próprio Flaubert sobre os constrangimentos sociais existentes para os intelectuais: a rigor, este é um tema flaubertiano. (Aliás, esta última constatação nos leva inclusive a uma relativização acerca do citado projeto do romancista de escrever um "livro sobre nada, sem vínculos exteriores", pois o que a análise de Bourdieu demonstra - ainda que sem o reconhecer explicitamente - é que a prática literária de Flaubert situa-se bem além do que ele declarava publicamente ou em correspondência!)

Todavia, a situação muda bastante de figura quando vamos analisar aqueles autores que elegem outros temas como seus motivos centrais; pense-se por exemplo nas obras de um James
Joyce ou de uma Virginia Woolf. Nelas, o que está em jogo é sobretudo um denso trabalho metalingüístico, em que a experiência de uma introspecção radicalizada dos personagens - diferentemente do que ocorre em Flaubert - vai para um primeiro plano muito evidente da narrativa. Sabemos que a própria possibilidade de tal introspecção só é dada em determinadas sociedades e a partir de um certo momento histórico; porém, apenas constatar isso seria trivial para o exercício da crítica literária. Em casos como estes, a proposta de investigação de Bourdieu teria muito pouco a nos dizer, a não ser que escolhêssemos como fonte de análise não os romances destes autores, mas suas declarações públicas como cidadãos (mais adiante veremos que, com algumas exceções, foi exatamente este o tipo de fonte documental majoritariamente utilizado por Bourdieu em sua análise dos defensores da arte pela arte).

Se nos indagarmos pelas razões que levaram nosso autor a proceder desta forma, talvez a principal delas seja uma aposta muito reiterada naquele suposto paralelismo entre a obra literária e as posições que seus autores ocupam no campo artístico e literário. Isto pode ser comprovado mesmo num momento mais avançado de As regras da arte quando, referindo-se ao fato de os artistas e literatos oriundos de um determinado extrato social terem preenchido posições correspondentes no campo intelectual e artístico, Bourdieu sustenta que: "Às diferentes posiçôes [...] correspondem tomadas de posição homólogas, obras literárias ou artísticas evidentemente, mas também atos e discursos políticos, manifestos ou polêmicas etc." (1996, pp. 261-262, grifos do autor).

De novo aqui, salta aos olhos o fato de que esta homologia sustentada pelo autor deixa em segundo plano a transfiguração estética operada pelo texto literário. Pois este último ruma para aquilo que um filósofo como Maurice MerleauPonty (1964, pp. 62-63) chamaria de o excesso de significação, oferta de sentido que a obra densa intelectual ou artística - nos faz. Quando isso ocorre, torna-se possível presenciar o caráter propriamente produtivo da obra de arte, sua capacidade de expressar o que estava apenas latente na própria experiência histórica. Para este tipo de 
obra, seminal, talvez se inverta o raciocínio que implicitamente supõe que "o contexto explica a obra”, pois existe também a obra que nos interpela e nos ensina, evidenciando aquilo que, sem o seu concurso, simplesmente não existiria. Neste caso, diríamos que é ela, a obra, quem nos analisa, e é preciso ter acuidade para registrar a singularidade deste evento.

A bem da verdade, há que se reconhecer que em algumas (poucas) passagens de As regras da arte o próprio Bourdieu chega próximo do tema do excesso de significação da obra. Pensamos especialmente naquele momento do texto em que ele afirma que é preciso diferenciar "entre as obras que são o puro produto de um meio e de um mercado e aquelas que devem produzir seu mercado e podem mesmo contribuir para transformar seu meio, graças ao trabalho de libertação do qual são produto [...]" (Bourdieu, 1996, p. 124).

Se esse eixo argumentativo fosse desenvolvido até as suas últimas conseqüências, provavelmente ele chegaria à tematização das características peculiares da transfiguração estética, fazendo-nos pensar, por exemplo, na precisa afirmação do artista plástico Paul Klee (2001): "A arte não reproduz o visível, mas torna visível”. O problema é que considerações como as anteriormente citadas são minoritárias no texto de Bourdieu (que não cita Klee...): na verdade, o sociólogo prefere se comprazer em enunciar repetidas vezes que a obra está como que contida no espaço de possibilidades que o campo oferece.

\section{$* * *$}

Em suma, o que está em jogo aqui é a complexa relação entre categorias particulares e categorias universais que a manifestação artística encena de modo muito expressivo. A contribuição de Bourdieu nos mostra de forma eloqüente que aqueles que acreditam que a manifestação artística expressa uma universalidade inquestionada incorrem num procedimento ingênuo, que consiste em tomar por atemporais fenômenos que na verdade respondem a injunções históricas muito precisas. É nesse âmbito que a elaboração de Bourdieu incide; é por aí que seu trabalho teórico avulta em importância e produz sentido. Isso posto, porém, resta intacta uma importante questão: como explicar a permanência - e a contínua reatualização - de certas obras que ultrapassam em muito aquele campo no qual foram originalmente produzidas? A lúcida recusa de um universal abstrato não deve nos fazer cair na polaridade simétrica e oposta: a fixação na particularidade de cada obra, tomada como única e irrepetível.

É com esta difícil questão que a teoria estética se debate há literalmente séculos, e ela demanda uma articulação precisa entre categorias singulares, históricas (como aquelas que Bourdieu nos apresenta com inegável competência) e categorias mais gerais, que dizem respeito aos fundamentos mesmo da experiência estética. Se a obra de arte vem ao mundo marcada por uma particularidade que a gerou (um "campo"), talvez o índice distintivo da boa obra seja aquele que permite que ela ultrapasse esta sua origem rumo a uma dimensão mais universal. E é precisamente neste ponto em que a concepção de Bourdieu merece ser cotejada com a de outros autores.

Nem de longe pretendendo aqui uma abordagem exaustiva da questão, mencionemos apenas que na história da filosofia, pensadores como I. Kant e G. W. Hegel se debruçaram sobre as marcas distintivas da experiência estética. Assim é que, respondendo à essencial pergunta: "por que cria o homem obras de arte?", este último filósofo teorizou longamente sobre o esforço humano de passagem do em si ao para si, que traz consigo uma dimensão da consciência da maior relevância, pois é por esta via que se obtém um alargamento da experiência que de outra forma seria impossível (Hegel, 1974, pp. 117-120). Bem sabemos que a ambição universalizante de Hegel recebeu certeiras críticas ao longo do século XX; porém, o fato é que presencia-se hoje uma revalorização de algumas de suas intuições seminais, despojadas dos elementos anacrônicos de seu sistema (basta lembrar da sofisticada abordagem psicanalítica do filósofo esloveno Slavoj Zizek que, em seu livro O mais sublime dos histéricos, recupera em contexto teórico diferenciado algumas das contribuições de Hegel).

Destarte, autores com orientação conceitual bem distinta do idealismo alemão - reconhecen- 
do a relevância da questão que se pergunta por que, afinal, os homens criam obras de arte - reconstruíram esta dialética em quadro conceitual diferenciado. Donde a hipótese de que a expressão artística é bem-sucedida quando consegue uma expansão da consciência de seus produtores e receptores, originando a percepção de seu pertencimento ao próprio gênero humano (cf. Lukács, 1966). Assim, a obra expressiva seria aquela que nos permite transcender nosso cotidiano mais limitado, iluminando dimensões essenciais de uma humanidade em devir. Estaríamos diante então, não de uma condição humana abstrata, mas sobretudo da possibilidade de universalização de uma certa experiência, que pode ser partilhada, ainda que com óbvias diferenças, não apenas pelos gregos da Antigüidade, ou por Shakespeare (continuamente reencenados mesmo nos dias de hoje), mas também por nós, homens contemporâneos. Desenvolver este tema nos levaria muito distante do objeto aqui em foco, mas que fique pelo menos anotada esta carência de um enfrentamento mais substantivo, por parte de Bourdieu, dos fundamentos sobre os quais se baseia o fenômeno estético.

Aliás, no que tange ao trajeto intelectual do mestre francês, os primeiros artigos que ele escreve sobre teoria estética - bastante anteriores ao livro As regras da arte - contêm, a nosso ver, uma concepção exageradamente determinista da práxis estética e literária. Com o passar do tempo, e com o amadurecimento que costuma acompanhar a produção de um autor, Bourdieu consegue atingir um patamar mais alto em sua reflexão, consignado precisamente em seu As regras da arte. (Esta abertura de perspectiva a que nos referimos já foi registrada - mas no que diz respeito a outros níveis da teoria do sociólogo - por alguns estudiosos de seu pensamento; dentre eles, podemos citar Catherine Paradeise (1981), em seu comentário sobre Le sens pratique ${ }^{2}$.)

Contudo, mesmo nesta fase posterior de Bourdieu, é possível detectar a coexistência de eixos argumentativos diferenciados: um que praticamente identifica a obra literária ao campo a que pertence seu criador (o passo seguinte da análise consistindo em fazer afirmações sobre a obra que, a rigor, se aplicam melhor ao seu autor como cidadão). O outro nível de argumentação corresponde às aquisições posteriores de Bourdieu, onde cabe não só aquela passagem citada de $A s$ regras da arte (que lucidamente distingue as obras que se esgotam no mercado daquelas que geram o seu próprio campo), como também uma consistente análise do estilo de Flaubert, criação singularizada do romancista, trabalho sobre a linguagem que lhe permite - e a seu leitor - uma "experiência intensificada do real" (1996, p. 129).

Entretanto, mesmo neste momento mais elaborado da reflexão bourdieusiana, aquela matriz conceitual anterior, mais "dura", persiste como estrutura de base sobre a qual se ergue, às vezes de modo contraditório, sua teoria estética. Como exemplo desta persistência, mencionemos ainda uma outra passagem muito significativa para as teses aqui em jogo, aquela onde são discutidos os efeitos da perda de raridade da obra de arte.

Neste passo de As regras da arte, Bourdieu sustenta que, tal como ocorre com as mercadorias destinadas ao consumo simbólico ostentatório (perfumes, roupas de grandes costureiros etc.), também a obra de arte perde sua eficácia simbólica quando é muito difundida. Para fundamentar esta afirmação, ele compara as peças musicais de Albinoni, Vivaldi e Chopin, supostamente desvalorizadas pelo efeito de uma excessiva divulgação, com o destino da clientela dos perfumes de Carven, composta por "mulheres elegantes mas envelhecidas que permanecem apegadas aos perfumes chiques de sua juventude e de mulheres mais jovens mas menos abastadas" (1996, p. 288).

A comparação é particularmente infeliz. Primeiro porque a equiparação imediata de uma peça musical com uma mercadoria acaba por desconsiderar exatamente aquilo que é mais singular na obra de arte: a transfiguração estética que ela realiza e que lhe permite atravessar um percurso histórico de longa duração. E, depois, mesmo se aceitássemos os termos desta comparação, sua validade seria questionável também por uma outra via. Poucos compositores eruditos são mais executados do que J. S. Bach, mas nem por esta "perda de raridade", para usarmos os termos de Bourdieu, o músico alemão perdeu o seu valor distin- 
tivo: permanece, ao contrário, como um vértice de valor para os mais exigentes apreciadores de música. Também na literatura poderíamos reiterar o exemplo de Shakespeare como autor continuamente encenado, adaptado, transposto para o cinema, mas que nem por isso viu diminuído seu valor (ao contrário dos perfumes de Carven...). Razões análogas a esta permitiram que Jeannine Verdès-Leroux, talvez a crítica mais ácida de Bourdieu, injustamente afirmasse que sua teoria estética não consegue ultrapassar um misto de "determinismo, finalismo e tautologia" (Verdès-Leroux, 1998, p. 170).

Conviria indagar por que motivo um sociólogo que tinha um acentuado interesse por filosofia como nos mostra Chauviré (1995) - reservou um espaço tão pequeno em sua análise para a singularidade estética, dimensão sem dúvida essencial para um aprofundamento neste campo da experiência humana. Talvez a resposta para esta questão possa ser encontrada nas afinidades de Bourdieu com o pensamento estruturalista (amplamente hegemônico na época em que ele publica seus primeiros trabalhos), que determinam várias das características de sua sociologia dos campos. Pois é um motivo desenvolvido pelo estruturalismo aquele que afirma incessantemente que as tomadas de posição dos agentes sociais devem ser vistas sobretudo como o efeito de uma estrutura que os sobredetermina. A crítica a esta suposição é hoje bem conhecida em ciências sociais: ela esvazia a capacidade de ação dos sujeitos, que comparecem na teoria desprovidos de seu poder de interagir com as determinações oriundas das estruturas sociais. (Curioso é notar que a capacidade de ação consciente dos sujeitos foi exemplificada pela própria ação política de Bourdieu ao final de sua vida, em sua militância intensa e aberta contra o neoliberalismo; lamentamos apenas que tal capacidade não tenha sido devidamente teorizada nos textos do autor aqui em foco!)

Lateralmente, observe-se também que não é apenas na reflexão sobre estética que se pode detectar esta característica homogeneizadora da teoria dos campos de Bourdieu. Em sua análise, bem mais recente, que versa Sobre a televisão, nosso autor desenvolve o tema das subjacentes relações de semelhança que estariam presentes entre os membros do que ele nomeia como o campo jornalisti$c o$, afirmando que "[...] pequenas diferenças às quais, subjetivamente, os diferentes jornalistas atribuem tanta importância mascaram as enormes semelhanças" (1997, p. 32). O texto prossegue sustentando a existência de análogas relações de proximidade, de pertencimento a um campo, entre o jornal Le monde diplomatique e a emissora TF1 (Idem, p. 58). Mas ora, também aqui a operação de Bourdieu realiza uma considerável homogeneização de diferenças. Le monde diplomatique é um jornal que não apenas dá espaço mas incentiva movimentos de oposição à lógica econômica ditada pelas grandes corporações internacionais (movimentos nos quais, reiteramos, o próprio Bourdieu desenvolveu uma atividade política muito lúcida a partir da década de 1990). Ao passo que a TF1 prossegue em sua programação de consumo mais imediato e bastante comprometida com uma visão de mundo conservadora. De resto, há que se convir que uma análise sociológica onde cabem manifestações jornalísticas tão distintas termina por fazer passar uma peneira com "furos muito largos" sobre os fenômenos que pretende estudar.

Também o exame daquele outro conceito fundamental da sociologia bourdieusiana, o de habitus, nos evidenciará esta afinidade mais profunda (mesmo que negada pelo autor...) com o pensamento estruturalista. Vejamos sua própria formulação do que seja o habitus:

O habitus, sistema de disposições inconscientes que constitui o produto da interiorização das estruturas objetivas e que, enquanto lugar geométrico dos determinismos objetivos e de uma determinação, do futuro objetivo e das esperanças subjetivas, tende a produzir práticas e, por esta via, carreiras objetivamente ajustadas às estruturas objetivas (Bourdieu, 1974, pp. 201-202).

Vale destacar que esta passagem praticamente faz com que as "estruturas objetivas" recubram todas as possibilidades de ação dos sujeitos (inclusive de seu futuro). Uma determinação desta ordem - que chega mesmo a se constituir como um determinismo fechado -, quando transposta 
para o campo literário, gerará aqueles efeitos comentados pouco acima: a análise bourdieusiana do texto literário finda por subsumi-lo inteiramente a seu contexto. A esta matriz estruturalista, somou-se também uma certa peculiaridade na escolha de Bourdieu de suas fontes de pesquisa. Pois, quando se examina os diferentes documentos nos quais ela foi baseada, verifica-se que, com a exceção da já citada análise de $A$ educação sentimental, houve um predomínio muito claro na correspondência dos literatos, bem como em suas declarações públicas, e nos artigos que escreviam para os periódicos da época.

A eleição preferencial deste tipo de fonte deixa em segundo plano uma análise mais desenvolta da obra literária propriamente dita, expressão singular da experiência estética. Na verdade, os documentos majoritariamente utilizados por Bourdieu põem em primeiro plano o artista como $c i$ dadão: ou seja, alguém que habita a polis e expressa uma série de considerações, sem dúvida marcadas por um pertencimento classista, sobre a vida de seu tempo. Mesmo quando se leva em conta o texto literário a que Bourdieu dedica mais atenção, o romance $A$ educação sentimental, é possível observar que trata-se de uma análise bastante sintética em comparação com o enorme número de páginas dedicadas pelo sociólogo às condições sociais que possibilitaram a emergência de um certo tipo de artista.

Ocorre que as conclusões válidas para o literato como cidadão podem se revelar no mínimo parciais para a obra que ele produz. Destarte, um literato que assume posições politicamente conservadoras pode deixar como legado artístico uma obra que, em sua dimensão estética, não se deixa recobrir por tais posições, pois elas foram metamorfoseadas pelo trabalho peculiar da criação literária. Assim, quando Bourdieu insiste na declaração de Baudelaire de que "O 2 de dezembro fisicamente me despolitizou. Não há mais idéias gerais" (apud Bourdieu, 1996, p. 76), tal afirmação pode servir sem dúvida para o cidadão Baudelaire - de fato desiludido com os rumos tomados pela política francesa da segunda metade do século XIX. Todavia, tudo muda de figura quando se procede a uma análise da lírica baudelairiana que, não obstante as declarações de seu autor, perma- nece atravessada, como veremos, por uma penetrante visão histórica e política do momento em que foi engendrada. Aliás, a referência a Baudelaire nos dará a oportunidade de brevemente cotejar a análise de Bourdieu com a de um outro pensador que também se ocupou do fenômeno estético.

$$
* * * *
$$

Referimo-nos a Walter Benjamin, que dedicou parte expressiva de sua elaboração teórica ao estudo de um período histórico próximo ao analisado por Bourdieu: a França de meados do século XIX. Vale lembrar que Benjamin foi tradutor de Baudelaire para o alemão, tendo um interesse tão acentuado em seus poemas que dedicou longos ensaios a eles. Curioso é notar, porém, que o leitor que disponha apenas do conceito bourdieusiano de campo intelectual e artístico, quando se debruçar sobre os densos textos de Benjamin se encontrará numa situação no mínimo desconcertante. Isso porque o Baudelaire que emerge destes ensaios é bastante diferente daquele que comparece na análise de Bourdieu: é um poeta cujo potencial contestatório - mesmo após o "2 de dezembro" - é enorme. Trata-se de alguém que, mesmo expressando um tipo bastante parcial de consciência histórica, ainda assim reteve traços essenciais do periodo.

Entre outros temas, Benjamin recupera a questão da raiva, do ímpeto revolucionário que estava presente nos poemas de Baudelaire, e faz uma analogia deste sentimento com as enormes tensões sociais não resolvidas do período: "Essa raivosa ira - la rogne -, esse rancor havia sido a estrutura psíquica que alimentara meio século de lutas de barricadas nos conspiradores profissionais de Paris" (Benjamin, 1985, p. 47). A leitura dos longos ensaios do filósofo alemão, como "A Paris do Segundo Império em Baudelaire" ou "Sobre alguns temas em Baudelaire", nos mostra a lírica do poeta expressando o pathos dos numerosos excluídos pela reação conservadora que se seguiu aos movimentos contestatórios de 1848. Recordemos que nas Flores do Mal - sua obra máxima - existem poemas que tratam dos velhos, das prostitutas, mendigos, enfim daqueles tipos que estavam até então proscritos de uma certa concepção de poesia. Ainda que - e esta ressalva 
é fundamental - a percepção consciente do próprio Baudelaire sobre o período apresente contradições (e inclusive marcas conservadoras, o que pode ser atestado pelos seus artigos de opinião e por sua correspondência), o fato é que sua obra propriamente poética termina por expressar bem mais do que o cidadão Baudelaire teria a dizer sobre a Paris do Segundo Império.

O resultado desta recuperação, por parte de W. Benjamin, do pathos peculiar ali existente faz com que os poemas baudelairianos ingressem no texto do filósofo como um momento constitutivo da argumentação, e não apenas como um objeto a ser abordado a partir de um ponto de vista alheio ao próprio poema. Apenas a título de ilustração, mencionemos a instigante hipótese benjaminiana de que é o tema da grande metrópole o motivo de fundo que subjaz à lírica de Flores do mal, fornecendo-lhe o estofo histórico e social do qual a obra retira sua força. Para demonstrar tal hipótese, Benjamin nos apresenta aqueles momentos em que o poeta registra as enormes modificações que estavam ocorrendo na experiência e na sensibilidade do habitante da grande cidade. Particularmente feliz nesta análise é a sua incorporação do poema baudelairiano "À une passante", que descreve o atordoamento do poeta ("crispado como um extravagante") por uma mulher que passa próximo a ele para logo se perder na multidão ao seu redor. Benjamin comenta que "O êxtase do citadino é um amor não já à primeira vista, e sim à última" (1980, p. 38): a moça desaparece no meio da multidão anônima, e o poeta intui que provavelmente nunca mais a verá. A partir deste motivo, são desenvolvidas considerações acerca de uma nova subjetividade que estava se formando naquele momento, que se caracterizava pela transitoriedade das relações pessoais, pela falta de referências estáveis, o que repercute na constituição de uma estrutura psíquica singular. E o filósofo nos mostra que os poemas de Baudelaire são um testemunho eloqüente desta condição: é a vivência do $c h o c$, dos eventos fragmentados - conforme o atesta também o poema sobre o jogo de azar, "Le jeu" -, que geram a incapacidade de se formar um sentido mais consistente acerca do transcurso da experiência. Não se tratando de postular o retorno a um momento his- tórico já superado, o que Benjamin faz é perquirir pelos signos da emergência de uma nova época, captada de forma poética (ainda que com os traços da lírica "maldita") em Flores do mal.

Lembremos ainda que o projeto mais geral que anima Benjamin é o de dar relevo àquelas vozes que foram silenciadas por um certo discurso vitorioso, fazer a chamada história a contrapelo, que se opõe ao registro oficial encontrado numa interpretação consoante aos interesses dominantes de uma época. Neste empreendimento, a obra literária desempenha um papel fundamental na ruptura da imagem consagrada de uma certa configuração histórica. É por isto que, ao invés de apenas ilustrar uma hipótese previamente constituída, ela (a obra) ingressa nos ensaios benjaminianos como um momento mesmo, precioso e insubstituível, da argumentação. Fato que nos faz pensar na produtividade da obra de arte, sua força expressiva que the permite iluminar uma certa constelação temporal. É certo que Benjamin registra em vários momentos as ambigüidades do homem Baudelaire, seu comprometimento com o sistema econômico e social que ele mesmo denuncia, mas isso não deve nos fazer perder de vista a força expressiva de seus poemas, testemunho de uma época que, metaforicamente, ainda hoje nos envia os sinais de suas tensões, ultrapassando seu contexto imediato e chegando até nós.

Voltando agora, e por fim, ao conceito bourdieusiano de campo intelectual e literário, reiteramos que o objetivo aqui não foi o de esvaziar sua importância, mas apenas cotejá-lo com outros estilos de crítica literária. Até porque, conforme já mencionado ao início deste artigo, trata-se de um conceito inegavelmente fecundo, que detecta relações de força que, sem o seu auxílio, permaneceriam simplesmente desconhecidas: nosso olhar ganha em abrangência quando nos damos conta, seguindo os passos de Bourdieu, de que existem subjacentes relações de reciprocidade e de oposição comandando as tomadas de posição dos literatos. O que se tentou fazer aqui foi apenas uma discussão sobre alguns limites no uso deste conceito, principalmente quando se trata de abordar aqueles artistas ou literatos que geraram uma obra muito potente, que transborda do campo constituindo uma forma de expressão que não apresen- 
ta solução de plena continuidade com o até então existente.

Talvez o grande desafio para os cientistas sociais que não desejem ser acusados de praticar um "reducionismo sociológico" (acusação infelizmente muito freqüente nos círculos filosóficos...) seja precisamente elaborar uma análise que consiga captar a força da obra literária. Quando se consegue isto, esta última ingressa no texto sociológico não apenas como ilustração de um argumento já constituído, mas com a sua potência significativa, naquilo que tem de mais essencial e que a diferencia de um mero espelhamento de uma realidade já existente. Momento necessário neste empreendimento é a acolhida de interpretações distintas sobre o mesmo fenômeno. Dito de outro modo: no que tange aos autores aqui abordados, nem de longe propomos que se faça uma escolha (empobrecedora) entre P. Bourdieu e W. Benjamin. Aliás, concordando neste particular com o primeiro autor, lembremos que "não se pode fazer a ciência avançar [...] a não ser à condição de fazer com que teorias opostas se comuniquem" (Bourdieu, 1983, p. 20).

\section{NOTAS}

1 Recorremos aqui à cuidadosa tradução brasileira destes artigos, feita por Sergio Miceli. (cf Bourdieu, 1974).

2 Em nosso país, embora reconhecendo a riqueza da teoria bourdieusiana dos campos, Renato Ortiz já havia detectado também o risco de "uma perspetiva imobilista do processo de reprodução" (Ortiz, 1994, p. 29).

\section{BIBLIOGRAFIA}

ACCARDO, Alain \& CORCUFF, Philippe. (1986), La sociologie de Bourdieu. Bordeaux, Le Mascaret.

BENJAMIN, Walter. (1985), "A Paris do Segundo Império em Baudelaire”, in F. R. Kothe (org.), Walter Benjamin, São Paulo, Ática.

(1980), "Sobre alguns temas em Bau- delaire", in Benjamin/Horkheimer/Adorno/Habermas (coleção Os Pensadores, vol. 48), São Paulo, Abril Cultural.

BOURDIEU, Pierre. (1974), A economia das trocas simbólicas. São Paulo, Perspectiva.

(1980), Le sens pratique. Paris, Editions de Minuit.

(1983), Questôes de sociologia. Rio de Janeiro, Marco Zero.

(1993), La misére du monde. Paris, Le Seuil.

(1996), As regras da arte. São Paulo, Companhia das Letras.

(1997), Sobre a televisão. Rio de Janeiro, Jorge Zahar.

BOURDIEU, Pierre \& HAACKE, Hans. (1999), $L i$ vre-troca: diálogos entre ciência e arte. Rio de Janeiro, Bertrand Brasil.

CHAUVIRÉ, Christiane. (1995), "Des philosophes lisent Bourdieu". Critique, 579-580: 548-562, ago.-set.

HEGEL, Georg W. F. (1974), "Estética: a idéia e o ideal”, in Hegel (coleção Os Pensadores, vol. 30), São Paulo, Abril Cultural.

KLEE, Paul. (2001), Sobre a arte moderna. Rio de Janeiro, Jorge Zahar.

LUKÁCS, Gyorgy. (1966), Contributi alla storia dell'estética. Milano, Feltrinelli.

MERLEAU-PONTY, Maurice. (1964), L'oeil et l'esprit. Paris, Gallimard.

ORTIZ, Renato. (1994), "Introdução", in R. Ortiz (org.), Pierre Bourdieu, São Paulo, Ática.

PARADEISE, Catherine. (1981), "Note de lecture sur Le sens pratique". Revue Française de Sociologie, 22: 636-642, out.-dez.

VERDÈS-LEROUX, Jeannine. (1998), Le savant et la politique: essai sur le terrorisme sociologique de Pierre Bourdieu. Paris, Grasset.

ZIZEK, Slavoj. (1990), O mais sublime dos histéricos. Rio de Janeiro, Jorge Zahar. 
BOURDIEU E O FENÔMENO ESTÉTICO: GANHOS E LIMITES DE SEU CONCEITO DE CAMPO LITERÁRIO

Maurício Vieira Martins

\section{Palavras-chave}

P. Bourdieu; Sociologia da literatura; Teoria estética; W. Benjamin.

Este artigo discute a contribuição de Pierre Bourdieu para uma sociologia do fenômeno estético, especialmente por meio do exame de seu conceito de campo literário. Num primeiro momento, são apresentados os ganhos da concepção bourdieusiana frente a uma apreensão ingênua do texto literário (que o encara apenas como produto de uma individualidade criadora). Num segundo momento, porém, sustenta-se a idéia de que o texto literário apresenta um "excesso de significação" que o referido autor parece ter dificuldades em captar, pois vincula de modo muito estreito a obra literária ao pertencimento social imediato de seu(s) produtor(es). O artigo se encerra com a proposta de aliar os melhores momentos da instigadora contribuição de Bourdieu com o trabalho de alguns outros pensadores (como W. Benjamin), que também se indagaram acerca da relevância do texto literário como documento fecundo para o entendimento de um certo período histórico.
BOURDIEU ET LE PHÉNOMẼNE ESTHÉTIQUE: GAINS ET LIMITES DE SON CONCEPT DE CHAMP LITTÉRAIRE

Maurício Vieira Martins

\section{Mots-clés}

P. Bourdieu; Sociologie de la littérature; Théorie esthétique; W. Benjamin.

Cet article analyse la contribution de Pierre Bourdieu à la sociologie du phénomène esthétique, en particulier par l'examen de son concept de champ littéraire. Dans un premier temps, nous présentons les gains relatifs à la conception établie par Bourdieu face à une appréhension ingénue du texte littéraire (qui le considère un produit de l'individualité créatrice). Néanmoins, dans un second temps, nous soutenons que le texte littéraire présente un "excès de signification", idée que Bourdieu semble avoir du mal à capter, car il lie de façon étroite l'œuvre littéraire à l'appartenance sociale immédiate de son (ses) producteur(s). Nous concluons l'article en proposant d'allier les meilleurs moments de la contribution instiguante de Bourdieu au travail d'autres penseurs (comme W. Benjamin), qui se sont également interrogés à propos de l'importance du texte littéraire en tant que document fécond pour la compréhension d'une certaine période historique.

\section{BOURDIEU AND THE AESTHETIC PHENOMENON: GAINS AND LIMITS IN HIS CONCEPT OF LITERARY FIELD}

Maurício Vieira Martins

\section{Keywords}

P. Bourdieu; Sociology of literature; Aesthetic theory; W. Benjamin.

The article discusses the contribution of P. Bourdieu to a sociology of aesthetics, examining in particular his concept of a "literary field." Initially the advantages of the bourdieusian position over an ingenuous understanding of literary text (that views the latter only as the product of a creative individuality) are presented. Subsequently, however, it is argued that the literary text presents an "excess of meaning" that the author appears to have difficulty in capturing because, in his conception, the work is too closely linked to the immediate social context of its originator or originators. The article eventually proposes that the best moments of his provocative contribution must be united to the work of other thinkers (such as W. Benjamin) that also questions the relevance of the literary text as a productive source for understanding a particular historical period. 